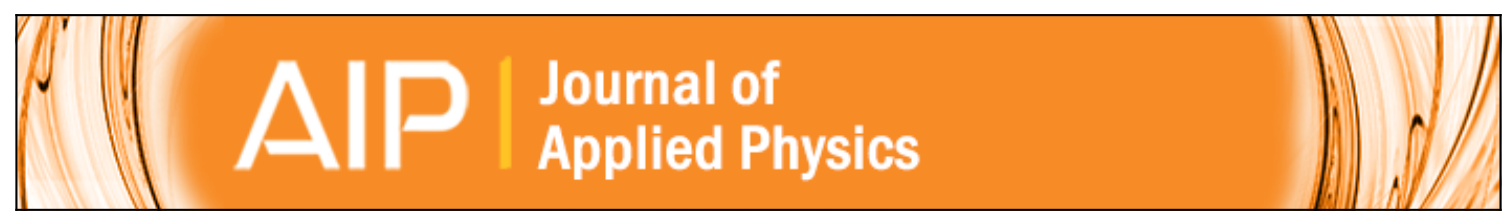

\title{
Recrystallization behavior of silicon implanted with iron
}

J. P. de Souza, L. Amaral, and P. F. P. Fichtner

Citation: Journal of Applied Physics 71, 5423 (1992); doi: 10.1063/1.350564

View online: http://dx.doi.org/10.1063/1.350564

View Table of Contents: http://scitation.aip.org/content/aip/journal/jap/71/11 ?ver=pdfcov

Published by the AIP Publishing

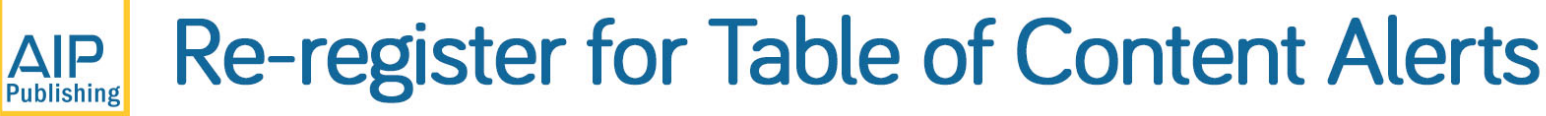

Create a profile. 


\title{
Recrystallization behavior of silicon implanted with iron
}

\author{
J. P. de Souza and L. Amaral \\ Instituto de Fisica, UFRGS, 91500 Porto Alegre, R.S., Brazil \\ P. F. P. Fichtner \\ Escola de Engenharia, UFRGS, 90000 Porto Alegre, R.S., Brazil
}

(Received 2 December 1991; acceptcd for publication 24 February 1992)

\begin{abstract}
The solid phase epitaxial growth (SPEG) of amorphized Si layers implanted with $\mathrm{Fe}\left(1 \times 10^{15}\right.$ $\mathrm{cm}^{-2}, 100 \mathrm{keV}$ ) was investigated in the temperature range from 500 to $550^{\circ} \mathrm{C}$ using Rutherford backscattering spectrometry. The push-out of $\mathrm{Fe}$ atoms by the moving amorphous-crystalline $(a-c)$ interface was observed during annealing, and enhancement of the recrystallization rate was induced by the presence of $\mathrm{Fe}$. These results are discussed in terms of a model that assumes that $\mathrm{Fe}$ atoms are trapped in the amorphous layer and released when they are reached by the moving $a-c$ interface during the SPEG process.
\end{abstract}

\section{INTRODUCTION}

Recrystallization via solid phase epitaxial growth (SPEG) of Si layers amorphized by ion implantation has been extensively studied during the last two decades. It is well established that the SPEG proceeds via a layer-bylayer reordering mechanism with an activation energy of about $2.7 \mathrm{eV} .^{1}$ The presence of impurities in these amorphized layers may significantly affect the recrystallization behavior depending on the impurity element and its concentration. The effect of the impurities on the SPEG process may be distinguished according to their solubility and diffusivity within the crystalline silicon ( $c$-Si) phase. ${ }^{2}$ Highly soluble slow diffusing elements (e.g., $\mathbf{B},{ }^{3} \mathbf{P},{ }^{2-4}$ $\mathrm{As}^{2-4}$ ) present in concentrations below their solubility limit cause an increase of the SPEG rate. In addition, during recrystallization most of the impurity atoms are incorporated into substitutional lattice sites, while their asimplanted profile may be nearly unchanged. ${ }^{2}$ When the impurity concentration exceeds the solubility limit, a significant fraction of the implanted atoms are "snowplowed" toward the sample surface by the moving $a-c$ interface (push-out effect) ${ }^{2,4}$ and the SPEG rate is reduced. This behavior has been observed, e.g., for $\mathrm{In}_{,}^{4,5} \mathrm{Sn},{ }^{5} \mathrm{Sb}^{5,6} \mathrm{Te}$, $\mathrm{Pb}^{4,8}$ and $\mathrm{Bi}^{4,9}$ By further increasing the implanted dose, the reduction of the SPEG rate may be such that nucleation and growth of precipitates may dominate the recrystallization process with consequent transformation of the amorphous $\mathrm{Si}(a-\mathrm{Si})$ phase to polycrystalline. ${ }^{2,4,10}$ In contrast, low solubility, slow diffusing impurities like $\mathrm{O}$ and $\mathrm{N}$ may retard ${ }^{11}$ or even inhibit ${ }^{5}$ the recrystallization due to the formation of chemical bonds with $\mathrm{Si}$ or precipitation. Furthermore, chemically inert and very low soluble elements like the noble gases can also affect the recrystallization significantly by the formation of gas-vacancy complexes or large gas bubbles. ${ }^{1-13}$

The influence of the SPEG process on the redistribution of low solubility by fast diffusing metal atoms has been studied for the cases of $\mathrm{Ag},{ }^{7} \mathrm{Au},{ }^{14} \mathrm{Cu},{ }^{1,9}$ and $\mathrm{Zn} .{ }^{15}$ The change in their implanted profile was characterized by the formation of a plateau-like profile located somewhere between the as-implanted profile and the sample surface. In order to explain these observations it has been suggested ${ }^{9}$ that fast diffusers cannot be trapped at the moving $a-c$ interface, and therefore diffuse away precipitating in the amorphous phase prior to recrystallization.

The annealing of Fe implanted into (111) oriented $\mathrm{Si}$ samples was studied by Wang et al. ${ }^{16}$ They found that the Fe profile does not redistribute during annealing performed at temperatures below $1100^{\circ} \mathrm{C}$. The complete recovery of the implantation damage was attained only for $\mathrm{Fe}$ doses less than the critical amorphization dose of $2.5 \times 10^{14}$ $\mathrm{cm}^{-2}$. For doses higher than the critical dose, a partial recovery of the implantation damage is observed to occur. Pivac et al. ${ }^{17}$ implanted $\mathrm{Fe}^{+}$into (100) oriented $\mathrm{Si}$ and annealed the samples at $1000^{\circ} \mathrm{C}$ for $2 \mathrm{~h}$. They determined that for doses below the amorphization level, the Fe distributes smoothly throughout the bulk. For doses above a given critical dose, the majority of the $\mathrm{Fe}$ atoms remain trapped in regions around the depth of the projected range, while a fraction of the dose diffuses into the bulk.

The present study describes a distinct redistribution behavior of Fe implanted in Si substrates under the SPEG process performed at $500-550^{\circ} \mathrm{C}$. To our knowledge, the present experiments show for the first time the push-out of $\mathrm{Fe}$ atoms during the SPEG of $a$-Si layer such that after the completion of the SPEG apparently all implanted $\mathrm{Fe}$ atoms become segregated into a thin layer at the sample surface. Similar segregation of fast diffusing impurities has been previously observed only in laser annealed samples implanted with $\mathrm{Zn},{ }^{15} \mathrm{Ag},{ }^{7} \mathrm{Fe},{ }^{18}$ and $\mathrm{Cu} .{ }^{9,19}$ However, such redistribution behavior was associated with the liquid phase epitaxial regrowth process.

\section{EXPERIMENTAL METHODS}

Silicon samples of $(100)$ orientation were preamorphized up to the depth of $220 \mathrm{~nm}$ by the combination of two $\mathrm{Ge}^{+}$implantations with doses of $5 \times 10^{14}$ and $3 \times 10^{14}$ $\mathrm{cm}^{-2}$ and energies of 200 and $50 \mathrm{keV}$, respectively. Subsequently, $\mathrm{Fe}^{+}$was implanted at the dose of $1 \times 10^{15}$ $\mathrm{cm}^{-2}$ and energy of $100 \mathrm{keV}$ in preamorphized and in virgin samples. The $\mathrm{Fe}^{+}$range parameters ${ }^{20}\left(R_{p}=85 \mathrm{~nm}\right.$ and $\Delta R_{p}=32 \mathrm{~nm}$ ) were chosen to locate the implanted profile within the preamorphized layer. A set of $\mathrm{Ge}^{+}$implanted samples was preserved against $\mathrm{Fe}^{+}$implantation to be used as control samples. All implantations were performed with the samples kept at room temperature. The 


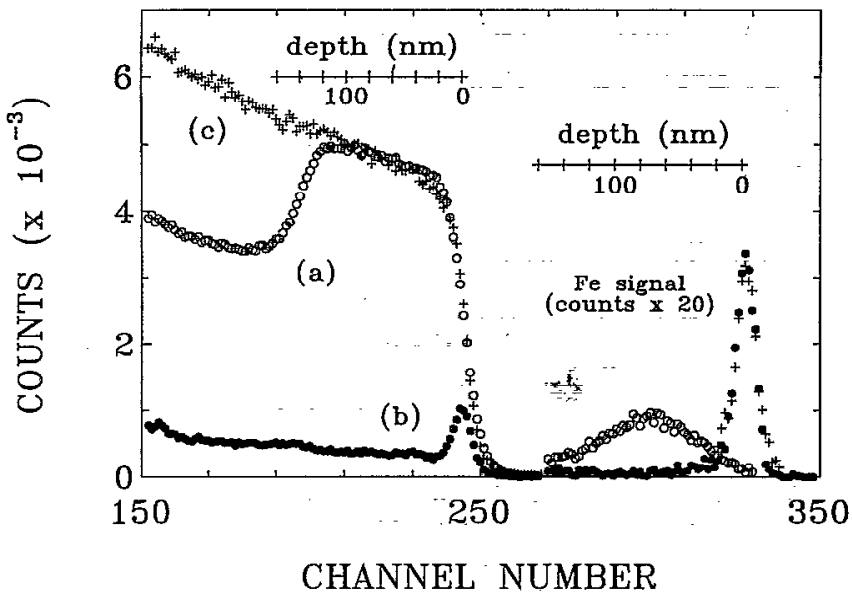

FIG. 1. Curve (a), $(100\rangle$ aligned RBS spectrum of as-implanted sample with $\mathrm{Fe}^{+}\left(100 \mathrm{keV}, 1 \times 10^{15} \mathrm{~cm}^{-2}\right)$. Curve (b), $\langle 100\rangle$ aligned and curve (c), random RBS spectra taken after an annealing at $550^{\circ} \mathrm{C}$ for $15 \mathrm{~min}$. Note the redistribution of the $\mathrm{Fe}$ atoms and the recrystallization of the $\mathrm{Si}$ substrate.

annealing runs were performed in high vacuum $(P=5$ $\times 10^{-7}$ mbar) in the temperature range from 500 to $550^{\circ} \mathrm{C}$ for times from 10 to $185 \mathrm{~min}$. One control sample was used in each annealing run. The samples were analyzed using Rutherford backscattering spectrometry (RBS) either with random incidence direction or aligned with the $\langle 100\rangle$ direction of the Si substrate. For the RBS analysis, we used a ${ }^{4} \mathrm{He}^{2+}$ beam with energy of $760 \mathrm{keV}$ from the ion implanter. The overall energy resolution of the RBS analysis was $14 \mathrm{keV}$.

\section{EXPERIMENTAL RESULTS AND DISCUSSIONS}

Figure 1 shows the aligned RBS spectra of a sample as-implanted with $\mathrm{Fe}^{+}$[spectrum (a)] and the aligned and random RBS spectra of the same sample after a subsequent annealing at $550^{\circ} \mathrm{C}$ for $15 \mathrm{~min}$ [spectrums (b) and (c), respectively]. The $\mathrm{Fe}^{+}$implantation caused the formation of an amorphous layer extending from the depth of $135 \mathrm{~nm}$ to the sample surface [see speclrum (a)]. This $a$-Si layer was completely recrystallized via SPEG during the considered annealing [see spectrum (b)]. It is evident in spectrum (b) or (c) that the push-out of the $\mathrm{Fe}$ atoms occurred during the SPEG. In these spectra, the peak of the $\mathrm{Fe}$ signal is located at the position corresponding to that of $\mathrm{Fe}$ atoms on the sample surface. They are distributed in a layer the thickness of which should be much smaller than the depth resolution of our RBS analysis ( $24 \mathrm{~nm}$ ), because the width at the mean height of the Fe peak in the RBS spectra practically coincides with the energy resolution of the RBS system ( $14 \mathrm{keV}$ ). All the Fe atoms are apparently occupying nonsubstitutional lattice sites, because the aligned and random $\mathrm{Fe}$ backscattering signals coincide. Furthermore, we note the absence of any noticeable residual defect distribution in the regrown layer as evidenced by the low backscattering yield of the $\operatorname{Si}\left(\chi_{\min } \cong 6 \%\right)$ in spec-

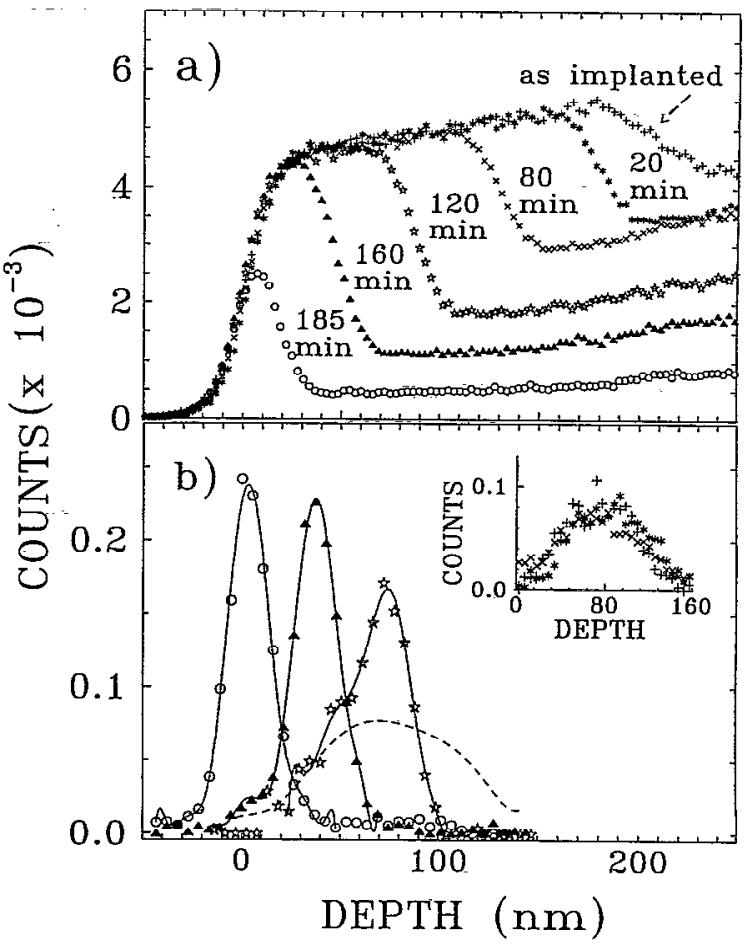

FIG. 2. Portions of the RBS spectra corresponding to the $\mathrm{Si}(\mathrm{a})$ and $\mathrm{Fe}$ (b) signals obtained from samples submitted to thermal treatments at $500^{\circ} \mathrm{C}$ with time duration ranging from 0 to $185 \mathrm{~min}$. The inset in (b) shows the $\mathrm{Fe}$ profiles of the as-implanted sample and of samples annealed at $500^{\circ} \mathrm{C}$ for 20 and $80 \mathrm{~min}$. The dashed curve in (b) represents the average of the three profiles shown in the inset.

trum (b). This yield is only slightly higher than that of a $\mathrm{Si}$ virgin crystal (not shown) whose $\chi_{\min }$ is about $4 \%$ for $\langle 100\rangle$ aligned RBS.

Figures 2(a) and 2(b) present the aligned RBS spectra of the samples co-implanted with $\mathrm{Ge}^{+}$and $\mathrm{Fe}^{+}$and submitted to sequential annealing at $500^{\circ} \mathrm{C}$. The contribution of the Ge backscattering signal is superimposed on that of $\mathrm{Fe}$ in our RBS spectra. However, in order to clarify the Fe redistribution behavior, the Ge backscattering signal was subtracted from all the spectra shown in Fig. 2(b). In order to show the correlation between the depth of the $a-c$ interface and the $\mathrm{Fe}$ redistribution, the spectra (convoluted with the detector resolution) were plotted in Fig. 2(b) using the channel scalc transformed to depth scale. The following features can be detected in Figs. 2(a) and 2(b):

(1) The movement of the $a-c$ interface as the annealing proceeds [see Fig. 2(a)] correlates with the modification of the Fe profile shown in Fig. 2(b).

(2) During the first $80 \mathrm{~min}$ of annealing, while the $a-c$ interface is below the Fe doped region, the Fe profile does not present any noticeable modification [see inset in Fig. 2(b)]. This suggests that the Fe diffusivity in the $a$-Si phase should be negligible at the temperature used. This strongly contrasts with the data tabulated in Ref. 21, from which the estimated diffusion length for $\mathrm{Fe}$ atoms in $c-\mathrm{Si}$ is about $170 \mu \mathrm{m}$ for the $80 \mathrm{~min}$ annealing at $500^{\circ} \mathrm{C}$.

(3) The movement of the $a-c$ interface across the $\mathrm{Fe}$ doped region causes the push-out of the Fe atoms, while 


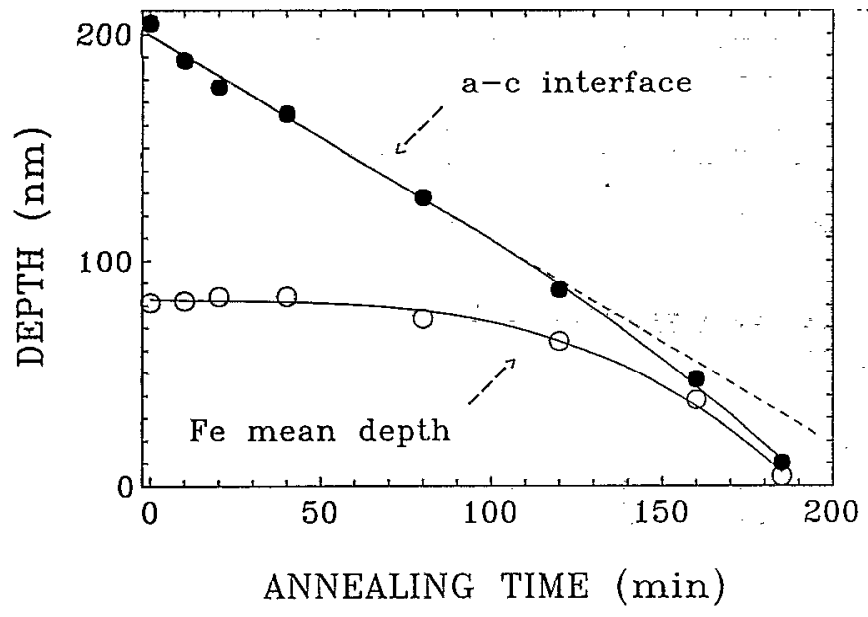

FIG. 3. Time dependence of the $a-c$ interface depth position (full circles) and of the mean depth of the Fe profile (open circles). The full lines were plotted to guide the eyes through the experimental points. The dashed line is the linear regression fit using the first five points.

the area under the backscattering peak of $F e$ is apparently kept constant. The Fe atoms move along with the $a-c$ interface toward the sample surface.

(4) After annealing for $185 \mathrm{~min}$, the SPEG is almost completed, and then the $\mathrm{Fe}$ atoms are located close to the surface. This Fe profile is similar to that observed for the sample annealed at $550^{\circ} \mathrm{C}$ for $15 \mathrm{~min}$ the channeling data of which are shown in Fig. 1.

Using data extracted from the spectra shown in Figs. 2(a) and 2(b), we plotted in Fig. 3 the depth of the a-c interface (full circles) and the mean depth of the Fe profile (open circles) as a function of the annealing time. Two additional points of information can be extracted from these data. First, in the control samples or in the region beneath the $\mathrm{Fe}$ doped region in the co-implanted sample (from the depth of 220-140 nm) the SPEG proceeds with velocity estimated to be $0.91 \mathrm{~nm} / \mathrm{min}$ (dashed line in Fig. 3 ). This result is in close agreement with the reported value of $1.0 \mathrm{~nm} / \mathrm{min}$ for the SPEG rate of $a-S i$ layers generated by $\mathrm{Si}^{+}$implantation in (100) Si substrates. ${ }^{22,23} \mathrm{Sec}-$ ond, after $80 \mathrm{~min}$ of annealing, the $a-c$ interface penetrates the $\mathrm{Fe}$ doped region, and then an enhancement of the SPEG rate by a factor up to 3-5 times is observed, occurring simultaneously with the push-out of $\mathrm{Fe}$ atoms by the moving $a-c$ interface [see Fig. 2(b)].

Furthermore, preliminary experiments using (111) oriented Si samples also demonstrated the push-out of $\mathrm{Fe}$ atoms during the SPEG process. However, the presence of $\mathrm{Ge}$ or of both $\mathrm{Ge}$ and $\mathrm{Fe}$ impurities seems to retard the SPEG rate in the (111) Si.

The presented results may be explained considering the $a$-Si phase containing a high density of homogeneously distributed traps for the $\mathrm{Fe}$ atoms. Very likely $\mathrm{Fe}$ atoms form iron silicide molecules and/or small silicide precipitates $\left(\mathrm{FeSi}_{x}\right)$. The low diffusivity of the Fe in the $a$-Si phase can be correlated with the thermal stability of the chemical compounds formed. The $\mathrm{FeSi}_{x}$ molecules and/or small precipitates are reached by the moving $a-c$ interface where they may decompose, probably to alleviate interfacial strains. These released $\mathrm{Fe}$ atoms in the presence of a high concentration of traps in the $a$-Si phase become trapped again after moving a distance much shorter than the amorphous phase thickness. The fraction of the Fe dose which should be introduced in the Si substrate is calculated to be below $0.05 \%$ taking into consideration the low solubility of $\mathrm{Fe}$ in the $c$-Si phase. ${ }^{24}$ Once in the $c$-Si phase, the Fe atoms may quickly diffuse toward the bulk or eventually become trapped once more in the $a$-Si phase. As the SPEG proceeds, the Fe atoms pile up in the $a$-Si phase close to the $a-c$ interface. At the completion of the SPEG process, the Fe atoms are located in a thin layer at the sample surface occupying nonsubstitutional lattice sites.

Further investigation is in progress to check the model presented under a variety of implantation and anncaling parameters.

\section{ACKNOWLEDGMENTS}

The authors are grateful to Agostinho Bulla, Alexandre Pino, and Carlos Cima for development of the automatic control for the channeling setup. This work was supported in part by Conselho Nacional de Desenvolvimento Científico e Tecnológico (CNPq) and Financiadora de Estudos e Projetos (FINEP).

${ }^{1}$ G. L. Olson and J. A. Roth, Mater. Sci. Rep. 3, 1 (1988).

${ }^{2}$ J. S. Williams, Nucl. Instrum. Meth. 209/210, 219 (1983).

${ }^{3}$ L. Csepregi, E. F. Kennedy, T. J. Gallagher, J. W. Mayer, and T. W. Sigmon, J. Appl. Phys. 48, 4234 (1977).

${ }^{4} \mathrm{~J}$. M. Poate and J. S. Williams, Ion Implantation and Beam Processing, edited by J. S. Williams and J. M. Poate (Academic, New York, 1984), p. 13.

${ }^{5}$ R. P. Thornton, R. G. Elliman, and J. S. Williams, Nucl. Instrum. Meth. B 37/38, 397 (1987).

${ }^{6}$ W. F. J. Slijkerman, P. M. Zagwijn, J. F. Van der Veen, G. F. A. Van de Waller, and D. J. Gravesteijn, J. Appl. Phys. 70, 2111 (1991).

${ }^{7}$ S. U. Campisano, G. Foti, P. Baeri, G. M. Grimaldi, and E. Rimini, Appl. Phys. Lett. 48, 118 (1986).

${ }^{8}$ G. Foti, E. Rimini, and S. U. Campisano, Phys. Status Solidi A 47, 533 (1980).

${ }^{9}$ S. U. Campisano, E. Rimini, P. Baeri, and G. Foti, Appl. Phys. Lett. 37, $170(1980)$.

${ }^{10}$ J. S. Williams and R. G. Elliman, Nucl. Instrum. Meth. 182/183, 389 (1981).

${ }^{11}$ E. F. Kennedy, L. Csepregi, T. W. Sigmon, and J. W. Mayer, J. Appl. Phys. 48, 4241 (1977).

${ }^{12}$ P. Revesz, M. Wittmer, J. Roth, and J. W. Mayer, J. Appl. Phys. 49, 5199 (1978).

${ }^{13}$ M. Wittmer, J. Roth, P. Revesz, and J. W. Mayer, J. Appl. Phys. 49, 5207 (1978).

${ }^{14}$ D. C. Jacobson, J. M. Poate, and G. L. Olson, Appl. Phys. Lett. 48, 118 (1986).

${ }^{15}$ T. N. Mustafin, G. A. Kachurin, V. P. Popov, N. V. Pridachin, V. G. Seryapin, and L. S. Smirnov, Proceedings of the IBMM Conference, edited by J. Gyulai, T. Lohner, and E. Pasztor (Central Research Institute for Physics, Budapest, Hungary, 1978), p. 727.

${ }^{16}$ P. W. Wang, H. S. Cheng, W. M. Gibson, and J. W. Corbett, J. Appl. Phys. 60, 1336 (1986).

${ }^{17}$ B. Pivac, A. Borghesi, M. Geddo, A. Stella, and L. Ottolini, J. Appl. Phys. 67, 2806 (1990).

${ }^{18}$ C. W. White, H. Naramoto, J. M. Williams, J. Narayan, B. R. Appleton, and R. S. Wilson, in Laser and Electron Beam Interaction with Solids, edited by B. R. Appleton and G. K. Celler (North-Holland, New York, 1982), p. 241. 
${ }^{19}$ P. Baeri, S. U. Campisano, G. Foti, and E. Rimini, Phys. Rev. Lett. 41, 1246 (1978).

${ }^{20}$ J. F. Ziegler, J. P. Biersack, and U. Littmark, in The Stopping and Ranges of Ions in Solids (Pergamon, New York, 1985).

${ }^{21}$ B. L. Sharma, Defect Diffusion Forum 70/71, 1 (1990).
${ }^{22}$ L. Csepregi, J. W. Mayer, and T. W. Sigmon, Phys. Lett. 54A, 157 (1975).

${ }^{23}$ L. Csepregi, J. W. Mayer, and T. W. Sigmon, Appl. Phys. Lett. 29, 92 (1976).

${ }^{24}$ E. R. Weber, Appl. Phys. A 30, 1 (1983). 